\title{
Erratum to: The melamine adulteration scandal
}

\author{
Kirti Sharma • Manish Paradkar
}

Published online: 20 February 2010

(C) Springer Science+Business Media B.V. \& International Society for Plant Pathology 2010

\section{Erratum to: Food Sec.}

\section{DOI 10.1007/s12571-009-0048-5}

Unfortunately a mistake was made in the name of the second author of this paper. It should read Manish Paradkar and not Manish Paradakar. org/10.1007/s12571-009-0048-5.

K. Sharma $(\bowtie) \cdot$ M. Paradkar ITC R \& D Centre, Food Technology Centre,

Peenya Industrial Area, 1st stage,

Bangalore 560058 Karnataka, India

e-mail: Kirti.Sharma@itc.in 